\section{Silver Zeolite as Promoter in Glycoside Synthesis. The Synthesis of $\beta$-D-Mannopyranosides.}

\section{PER J. GAREGG and PETRA OSSOWSKI}

Department of Organic Chemistry, Arrhenius Laboratory, University of Stockholm, S-106 91 Stockholm, Sweden

Despite sustained efforts, ${ }^{1-13}$ the synthesis of $\beta$-D-mannopyranosides remains a problem, particularly in the mannosylation of protected carbohydrates with one free hydroxyl group of low reactivity. $\beta$-D-Mannopyranosyl residues occur in a number of natural products, some of which are of biological significance, and the efficient construction of $\beta$-D-mannopyranosyl linkages is therefore a matter of some importance. The use of insoluble silver promoters in the complete absence of Lewis acids has been advocated for this purpose. ${ }^{11-13}$ Under these conditions, when equilibration at the anomeric centre of the glycosyl halide is suppressed, anomeric inversion of configuration is thought to predominate in the glycosylation reaction. ${ }^{13}$ Thus, starting from an $\alpha$-D-mannopyranosyl halide with a non-participating group in the 2-position, a $\beta$-D-mannopyranoside would be produced in the glycosylation. We now report the use of a novel, insoluble silver promoter, which gives improved yields in preparations of $\beta$-D-mannopyranosides. In our hands, the promoter, is more readily prepared than is silver silicate. ${ }^{12}$

Starting materials and products are represented by formulae 1-12. Relevant physical constants for the compounds obtained and other data are given in Table 1. All compounds obtained were syrups. The yields and

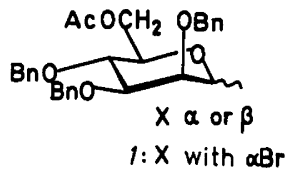

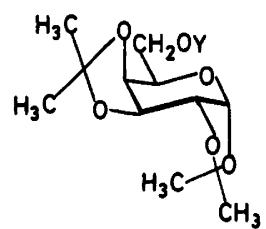

$$
\begin{array}{ll}
2: Y=H & 5: Y=H \\
3: Y=\beta X & 6: Y=\beta X^{18} \\
4: Y=\alpha X & 7: Y=\alpha X
\end{array}
$$

$\mathrm{Bn}=\mathrm{C}_{6} \mathrm{H}_{5} \mathrm{CH}_{2}$

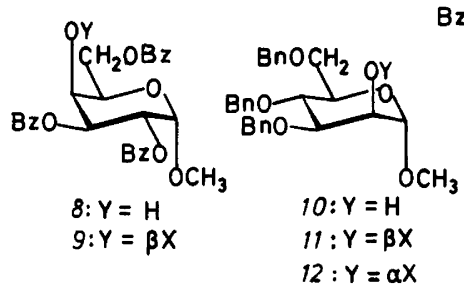

stereoselectivity for $\beta$-D-mannosylation are good for primary hydroxyl groups and for reactive secondary ones (compounds 2 and 5). The HO-4 of galactopyranosides has low reactivity, nevertheless, an acceptable yield of the $\beta$-D-mannoside 9 was obtained. Previous attempts at $\beta$-D-mannosylation at the $\mathrm{HO}-2$ of 10 have given poor results. ${ }^{9,10}$ In the present work, the $\beta$-D-mannoside 11 was obtained with moderate stereoselectivity.

Experimental. General methods were the same as those reported before. ${ }^{14}$

Glycosylation method. Mortared $4 \AA$ molecular sieves (Union Carbide, $25 \mathrm{~g}$ ) were stirred with

\begin{tabular}{|c|c|c|c|c|c|c|c|}
\hline Compound & 3 & 4 & $6^{18}$ & 7 & 9 & 11 & 12 \\
\hline $\begin{array}{l}\text { Yield }(\%) \\
{[\alpha]_{\mathrm{D}}^{20}\left({ }^{\circ}, \mathrm{CHCl}_{3}\right)} \\
\left.\delta_{\mathrm{c}} \text { (p.p.m., } \mathrm{CDCl}_{3}\right) \mathrm{C}-1\end{array}$ & $\begin{array}{c}83 \\
-55 \\
96.52 \\
10266\end{array}$ & $\begin{array}{l}15 \\
-18 \\
- \\
-\end{array}$ & $\begin{array}{c}61 \\
-85 \\
95.57 \\
9976\end{array}$ & $\begin{array}{c}9 \\
-21 \\
95.47 \\
0913\end{array}$ & $\begin{array}{r}33 \\
+52 \\
97.38 \\
10254\end{array}$ & $\begin{array}{l}50 \\
-29 \\
98.15 \\
0952\end{array}$ & $\begin{array}{l}21 \\
+8 \\
99.42 \\
99.86\end{array}$ \\
\hline $\begin{array}{l}J_{\mathrm{C}-1, \mathrm{H}-1}(\mathrm{~Hz}) \\
J_{\mathrm{C}-1^{\prime}, \mathrm{H}-1^{\prime}}(\mathrm{Hz}) \\
\delta_{\mathrm{H}}(\mathrm{p} . \mathrm{p} . \mathrm{m} .) \\
J_{1^{\prime}, 2^{\prime}}(\mathrm{Hz})\end{array}$ & $\begin{array}{l}180.7 \\
155.0 \\
4.47(d)^{a} \\
<0.5\end{array}$ & $\begin{array}{l}- \\
\overline{5} .00 \mathrm{~d}^{b} \\
1.2\end{array}$ & $\begin{array}{l}171.0 \\
157.5 \\
4.94(\mathrm{~d}) \\
<0.5\end{array}$ & $\begin{array}{l}168.5 \\
170.9 \\
4.88 \mathrm{~d}^{a} \\
1.6\end{array}$ & $\begin{array}{l}173.4 \\
153.8 \\
4.38(d)^{a} \\
<0.5\end{array}$ & $\begin{array}{l}166.7 \\
155.6 \\
4.57(d)^{a} \\
<0.5\end{array}$ & $\begin{array}{l}170.9 \\
170.9 \\
5.20 \mathrm{~d}^{b} \\
1.4\end{array}$ \\
\hline
\end{tabular}
silver nitrate $(12.5 \mathrm{~g})$ in water $(50 \mathrm{ml})$ at room

Table 1. Selected physical data for disaccharide derivatives obtained.

${ }^{a} \mathrm{CDCl}_{3} \cdot{ }^{b}\left(\mathrm{CD}_{3}\right)_{2} \mathrm{CO}$.

0302-4369/83 $\$ 2.50$

(C) 1983 Acta Chemica Scandinavica 
temperature in the dark for $2 \mathrm{~h}^{15,16}$ The mixture was filtered, the residue was washed with water $(3 \times 50 \mathrm{ml})$ then with acetone $(50 \mathrm{ml})$, and kept at $190^{\circ} \mathrm{C}$ for one day. The monohydroxy compound to be glycosylated $(2,5,8$ or $10,1 \mathrm{mmol})$ and 6- $O$-acetyl-2,3,4-tri- $O$-benzyl- $\alpha$-D-mannopyranosyl bromide $(1,1.5-2 \mathrm{mmol})$ in toluene (preparation of compounds 9,11 and 12) or dichloromethane (preparation of compounds 3 , 4,6 , and 7) were stirred at room temperature with silver zeolite $(1.5-2 \mathrm{~g})$. The reaction was monitored by TLC. Reaction times varied from a few hours to overnight. The reaction mixture was filtered and the filtrate concentrated. The desired products were obtained after chromatography on silica gel, ${ }^{17}$ using toluene-ethyl acetate as irrigant.

Full $400 \mathrm{MHz}{ }^{1} \mathrm{H}$ NMR data for all disaccharides in the Table are available upon request from this Department (PJG).

Acknowledgements. We are indebted to Professor Bengt Lindberg for his interest, to the Swedish Board for Technical Development and the Swedish Natural Research Council for financial support as well as a maintenance grant from the latter (to P.O).

1. Gorin, P. A. J. and Perlin, A. S. Can. J. Chem. 39 (1961) 2474.

2. Bebault, G. M. and Dutton, G. G. S. Carbohydr. Res. 37 (1974) 309.

3. Ekborg, G., Lindberg, B. and Lönngren, J. Acta Chem. Scand. 26 (1972) 3287.

4. Borén, H. B., Ekborg, G., Eklind, K., Garegg, P. J., Pilotti, A. and Swahn, C.-G. Acta Chem. Scand. 27 (1973) 2639.

5. Paulsen, H. and Lockhoff, O. Tetrahedron Lett. (1978) 4027.

6. Wulff, G. and Wichelhaus, G. Chem. Ber. 112 (1979) 2847.

7. Garegg, P. J. and Iversen, T. Carbohydr. Res. 70 (1979) C13.

8. Garegg, P. J., Iversen, T. and Johansson, R. Acta Chem. Scand. B 34 (1980) 505.

9. Srivastava, V. K. and Schuerch, C. J. J. Org. Chem. 46 (1981) 1121.

10. Srivastava, V. K. and Schuerch, C. J. Carbohydr. Res. 100 (1982) 411.

11. Paulsen, H., Lebuhn, R. and Lockhoff, $O$. Carbohydr. Res. 103 (1982) C7.

12. Paulsen, H. and Lockhoff, O. Chem. Ber. 114 (1981) 3102.

13. Paulsen, H. Angew. Chem. Int. Ed. Engl. 21 (1982) 155.

14. Garegg, P. J., Hultberg, H. and Oscarsson, S. J. Chem. Soc.Perkin Trans. 1 (1982) 2395.
15. Rothmund V. and Kornfeld, G. Z. Anorg. Allg. Chem. 103 (1918) 129.

16. Kornfeld, G. Z. Elektrochem. 23 (1917) 173.

17. Still, W. C., Kahn, M. and Mitra, A. J. Org. Chem. 43 (1978) 2923.

18. Garegg, P.J., Henrichson, C., Norberg, T. and Ossowski, P.Carbohydr. Res. Submitted.

Received February 2, 1983 